\title{
The challenges of providing safe sanitation as a public good in DKI Jakarta
}

\author{
Murwenda $^{1 *}$ Inayati $^{1}$, Haula Rosdiana ${ }^{1}$, and Lucas Filberto Sardjono ${ }^{1}$ \\ ${ }^{1}$ Department of Fiscal Administrative Science, Faculty of Administrative Science, Universitas \\ Indonesia, Depok 16424, Indonesia
}

\begin{abstract}
The crucial role of wastewater management contributes to the need for full government support. The impact of water pollution is a significant challenge to human health and well-being, which is one of the priorities of sustainable development, namely achieving universal and equitable access to safe and affordable drinking water and sanitation by 2030. DKI Jakarta is one of the major Indonesian cities facing Domestic Wastewater Management System (SPALD) challenges. This study used a constructivist paradigm and a qualitative approach. The data was gathered through field research and Focused Group Discussion. This study aims to analyze the challenges in providing safe sanitation as a public good in DKI Jakarta. This study has shown that PD PAL Jaya, SPALD operator in DKI Jakarta, has encountered several challenges, including the challenge of constructing the infrastructure due to the absence of the SPALD pipeline network in City Planning. Lack of private sector investment and insufficient state/local budget support slow progress in improving sanitation infrastructure. Public apathy concerning wastewater management problems and believing that this problem should require government interference also exacerbate the government's challenge. Consider their characteristics as public services; government intervention is critical to ensure that these services are delivered safely and adequately.
\end{abstract}

\section{Introduction}

\subsection{Background research}

Wastewater management is one of the most critical public health interventions in human history and has contributed to a significant reduction in waterborne diseases over the past century [1]. The critical role of wastewater management causes this sector to require full support from the government. Innovations in the wastewater management sector can alter the wastewater sector's policies regarding billing, taxation, licensing, and monitoring [1,2]. Apart from the tax aspect, financing this sector continues to be an essential concern for the government.

Water contamination is currently a significant threat to human health and well-being, one of the Sustainable Development Goals (SDGs) targets, namely achieving universal and

\footnotetext{
* Corresponding author: murwendah09@ui.ac.id
} 
equitable access to safe and affordable drinking water and sanitation sector by 2030 . The World Bank stated that there were 780 million people without access to clean water until 2014 and more than 2 billion people on earth had no access to sanitation. It leads to a high mortality rate and material loss, reaching $7 \%$ of the world's Gross Domestic Product (GDP) [3].

Almost all urban systems face challenges in providing safe, affordable, functional, and sustainable sanitation [4]. Factors such as constrained political willingness, inadequate technical, financial, and institutional capacity, and failure to integrate safe sanitation into broader urban development have led to unsustainable systems and missed opportunities to resolve urban sanitation overlaps and interactions challenges. The integration of urban development with sustainable sanitation development has tremendous potential to catalyze efforts and achieve the SDGs [4]. On the other hand, many studies have linked the context of sanitation and wastewater management to human rights issues. Kim et al. (2014) claim that the human rights concept highlights the negative consequences of water contamination and inadequate wastewater management, resulting in violations of human rights to water, sanitation, health, food, and others [5]. The state should protect its population from violations of their human rights to avoid being contaminated by others.

In 2011, the World Bank conducted a study on urban sanitation's political economy in several developing countries, such as Brazil, India, Indonesia, and Senegal. The "political economy of sanitation" refers to the social, political, and economic processes and actors involved in determining the level, nature of the investment, and the provision of sanitation services. Sanitation issues in Indonesia tend to be seen as private households' problems instead of a state obligation, although the government has increased interest in this sector through limited investment [6].

The study found that Indonesia's sanitation investment appears to be constrained by authoritarian rule's historical context, where advocacy is strenuous. Socio-political views both inside and outside the government indicated that sanitation is a personal responsibility. For cultural reasons, sanitation is generally not a subject that is common or quickly addressed within society. The central government has not attempted to change the perception that sanitation is solely a household problem. It is peculiar that all Indonesian socio-economic classes show a low degree of awareness and concern for sanitation issues. Public sanitation investment in Indonesia's urban areas has been low for decades, and much of the investment comes from private households or particular sectors only. These variables have a substantial long-term impact on the common community knowledge and demand for effective and safe waste management facilities and services [6].

DKI Jakarta is Indonesia's major cities facing challenges related to the Domestic Wastewater Management System (SPALD). With 10,177,924 people [7], the Provincial Government of DKI Jakarta is facing problems related to Clean and Healthy Lifestyle. One of the problems is that about 475,000 people (117,000 households) do not have septic-tanks for latrine disposal. Of the total latrines owned by residents, only $63.55 \%$ are in proper condition. The latrine's inadequate condition causes groundwater and surface/river water pollution by the feces collected therein.

Consequently, in DKI Jakarta, river water cannot function as a source of raw water for drinking purposes for the population. Another issue arises when a resident owns a latrine, albeit improper, suggesting that the user/owner still practices open defecation. Ultimately, it has repercussions for the supply of clean water from rivers. Currently, only $4 \%$ of DKI Jakarta's raw water needs are met by the Ciliwung River due to the river water's low quality. It can minimize if adequate SPALD is available in DKI Jakarta.

Only a small proportion of domestic wastewater management in DKI Jakarta is currently integrating with the piping system [8]. PD PAL Jaya provides this piping system as the wastewater management operator owned by the DKI Jakarta government. Most 
people still use septic tanks planted around their houses, which will then be transported by private companies to the domestic wastewater management installation or disposed of into rivers. The majority of society still does not have access to clean toilets and therefore practices open defecation.

Domestic wastewater management, including the issue of investment and its provision by the state as a public good, is the government's responsibility. Commodities in the form of water and sanitation often cause debate regarding the status of both as public goods or not. Water is a precious resource. The limited water resources and water scarcity will become increasingly difficult in the face of competition for access to water, particularly concerning the option of water resource allocation [9]. In contrast to other natural resources, water resources have several unique characteristics, which means the conventional market mechanisms may result in inefficient and inequitable water resource allocation. Based on this background, this study was conducted to analyze the challenges in providing safe sanitation as a public good in DKI Jakarta.

\subsection{Theoretical framework}

Musgrave and Musgrave (1993) state that the government has three functions: fiscal function, namely, allocation, distribution, and stabilization [10]. Providing public goods and services is the government's implementation of the allocation function. Economic law states that the market (private sector) will only provide goods and services to generate profits (private goods). Meanwhile, the state's public goods that do not generate profits must be provided as it will not be available in a free market system [11]. It is argued that there are two reasons why this public good is not available in the purely free market, namely variable costs will not escalate regardless of the increase of people's consumption (non-rivalry) and difficulties to enforce restrictions on people who consume the goods/services (non-excludability). However, these two explanations are not sufficient because the main reason the government must perform the allocation function is due to market failure. Another factor that causes the government to provide public goods or services is related to a) externalities and b) its essential role for developing a country, mainly concerning achieving the vision, mission, or programs of the government.

In the context of sanitation, one can determine the degree to which sanitation can become a public or private good. In this case, it may be argued that sanitation's basic needs cause it to be public good unless managed or used by certain parties and for a particular scope. Essentially, water and sanitation can be either a public good or a private good. It is important to note that water is not entirely qualified as a private good, which can be traded conventionally, given the current market mechanisms can lead to an inefficient allocation of water resources. On the other hand, the unique characteristics of water resources can be allocated efficiently by the market mechanism by taking into account the need for the water usage in order to ensure that the allocation can be carried out efficiently and equally, by taking into consideration the type, resources, and use.

The water commodity was once (could) be considered a free good. Although water is widely accepted as an economic commodity, water can currently be considered a public good $[12,13]$. Water supply services and wastewater services are characterized as 'noncompetitive' (non-rivalry) and 'non-excludable' in terms of consumption. The social value of services (wastewater) is much greater than the economic value; it is impossible not to provide these services [13]. Exceptions to the provision of this service can only be rendering under exceptional terms. If these services are exempted/excluded, the costs (e.g., public health or social disparities) will be much higher than the number of subsidized payments the government would have to make to provide such services. 
In general, the government has several public goods or public services, such as tertiary health care services, preventive health care services, community sanitation, drinking water supply networks, and primary education, each of which has its characteristics. According to Batley and Mclouglin (2015), community sanitation is categorized as public (merit) goods that have the following characteristics, as mentioned in Table 1 [14].

Table 1. The Characteristics of Community Sanitation as Public Goods [14]

\begin{tabular}{|c|c|c|}
\hline & Characteristics & Community Sanitation \\
\hline Nature of good & Rivalry & Low \\
\hline Market Failure & Mow & Low \\
\hline & Positive \& negative externalities & High \\
\hline Task & Information asymmetry & Medium \\
\hline & Measurability \& visibility of outputs & Low \\
\hline & Discretion of staff & Low \\
\hline & Transaction intensity & Medium \\
\hline Demand & Provider autonomy & Low \\
\hline & Territoriality & High \\
\hline Political Salience & & High \\
\hline
\end{tabular}

\section{Method}

This research employed a constructivist paradigm and a qualitative approach. The data was collected using field research and Focused Group Discussion (FGD). Field research was implemented at SPALD DKI Jakarta, which is managed by PD PAL Jaya. Furthermore, FGD was conducted twice with the Coordinating Ministry for Economic Affairs, Ministry of Public Works and Public Housing, Directorate General of Taxes - Directorate of Tax Regulations II, Section VAT, Fiscal Policy Agency, Ministry of Home Affairs, Ministry of National Development Planning of the Republic of Indonesia/National Development Planning Agency (BAPPENAS), and Communication Forum for National Wastewater Operators (Forkalim). In analyzing the data, the researchers conducted qualitative data analysis within three simultaneous activities: data reduction, data presentation, and concluding/verification using content analysis techniques.

\section{Results and discussion}

Fecal sludge management is generally implemented by an institution known as Fecal Sludge Management Installation (IPLT). IPLT is a facility used to carry out urban fecal waste management activities where the supply of sludge comes from the local management 
system, which will then be transported by a fecal suction fleet assigned from the fecal suction business or the local government [15]. Fecal sludge management will produce dry sludge and treated wastewater separated from the sludge, which can be reused as soil or fertilizer and as process water in IPLT or for plant watering purposes [16].

In the context of domestic wastewater management policies in Indonesia, the wastewater management approach is divide into two, namely centrally (piped) or locally (non-piped) based on the provisions under the Regulation of the Minister of Public Works and Public Housing No. 4 of 2017 concerning the Implementation of the Domestic Wastewater Management System. In Situ SPALD (SPALD-S) is a management scheme carried out by treating domestic wastewater at the source location. It has the sludge outputs transferred to the Fecal Sludge Management Sub-System after it is treating. Meanwhile, the Centralized SPALD (SPALD-T) is system management carried out by draining domestic wastewater from sources to the Centralized Management Sub-system to be treated before discharge to surface water bodies.

As a wastewater management operator, PD PAL Jaya's business activities consist of (1) an off-site system (sewerage system), (2) an on-site system, (3) regular desludging, (4) recycle, and (5) operation and maintenance. For on-site services, PD PAL Jaya has 3 IPLTs with various wastewater service capacities, namely IPLT Setiabudi (42,768 m3/day), IPLT Duri Kosambi (900 m3/day), and IPLT Pulo Gebang (900 m3/day). Sewerage service (offsite) is carry out by utilizing Zone 0 services with a pipe length of $96.2 \mathrm{~km}$ with a service coverage of $11.08 \%$ is equivalent ( 1.1 million population). There are 581 customers and 2,092 customers who are using this off-site service [8].

\subsection{Wastewater management service challenges as a public service or merit goods (services)}

Market failure in countries worldwide is a failure to provide/produce goods or services classified as public goods/public services. This phenomenon is often referring to as the failure of provision. One of the government's duties includes providing goods or services classified as public goods/public services. The challenges in establishing a proper and safe wastewater management infrastructure in DKI Jakarta are primarily related to technical and financial aspects.

First, it regards technical aspects concerning the development of domestic wastewater management infrastructure. The DKI Jakarta government, through PD PAL Jaya, has set a target to improve public access to better pipeline-based management of domestic wastewater to ensure adequate environmental sanitation for the community. However, PD PAL Jaya has experienced a range of challenges during its implementation, including the difficulty of developing the network due to the absence of the domestic wastewater management pipeline infrastructure in City Planning since the beginning of the project [8, 18]. The pipeline infrastructure network's construction is experiencing difficulties as nearly all city areas have been used to construct buildings and infrastructure for roads, railways, and Mass Rapid Transit (MRT) Indonesia. In terms of governance, coordination between ministerial/institutional actors is crucial to improve sanitation infrastructure in DKI Jakarta. In general, the challenge of coordination and construction correlates with the difficulty of managing the development of infrastructure for piped gas lines, electricity networks, telecommunications networks, drinking water pipes, MRT, and pedestrian roads so that they do not overlap with the construction of wastewater infrastructure $[8,17]$.

Second, as in several developing countries, only a few domestic waste management services are provided by Indonesia's private sector at present. In this case, only PD PAL Jaya plays a role in wastewater management services with status as BUMD in DKI Jakarta. To overcome the limited investment of sanitation and wastewater in DKI Jakarta, the 
Ministry of Public Works and Public Housing, through the Directorate General of Human Settlements, collaborates with the Japan International Cooperation Agency (JICA) to assist the Provincial Government of DKI Jakarta in building SPALD with a piping network called the Jakarta Sewerage Development Project (JSDP). This project aims to improve sanitation access in DKI Jakarta and protect water quality from domestic waste (household) [17].

A variety of factors contribute to the private sector's lack of involvement and interest in doing wastewater management business, namely SPALD requires a relatively large investment, such as land for domestic wastewater management, machinery/equipment, and piping network infrastructure. Currently, the fixed assets used by Regional Drinking Water Companies (PDAMs) and agencies to carry out wastewater management are part of a grant from the central government, specifically the Ministry of Public Works and Public Housing financed by the state budget, and local governments funded by local government budget and donor agencies.

To finance wastewater management services, the government can charge fees, remove subsidies for industries and agriculture, or impose other levies such as environmental taxes. However, these funding sources are certainly not enough to finance all wastewater management costs. Even in many developed countries, investment and wastewater management still have to be financed through budget allocations or donor support [17]. In addition to fees for disposal and management of wastewater, which are generally collect as sources of funding, other economic instruments such as taxes or other levies can promote community sanitation behavior [19].

Wastewater management has long been neglected [5]. The cost of adequate wastewater management is an essential and substantial matter, compared to the costs that would arise when wastewater management is not carried out. If water contamination persists and forsaken, it will result in massive water pollution and reduce economic benefits, which will impact the health sector and education productivity [20]. The benefits of prevention and treatment far outweigh the long-term costs of non-action [19]. Studies on economic returns from sanitation interventions show that septic tanks and treated sewerage have a cost to benefit ratio of 1:4 in the Philippines $[18,20]$ and 1:2,3 in Indonesia. This ratio compares the downstream impact of water pollution between the costs and benefits of domestic and industrial wastewater management, particularly in Indonesia [18].

Third, it is not easy to obtain the Break Event Point (BEP) in the wastewater treatment business in the medium term or even in the short term due to domestic wastewater management services, especially pipeline services, which have unique characteristics elaborated in the next part. As an illustration, the Communication Forum for National Wastewater Operators (Forkalim), which established in 2015 only has six organization members, consists of: (1) PD PAL Jakarta; (2) PD PAL Banjarmasin; (3) PDAM Tirtanadi; (4) PDAM Surakarta City; (5) PDAM Balikpapan; and (6) Regional Public Service Agency for Wastewater in Bali Province. Offices manage the rest of the SPALD under the local government with general types of services in the form of, among other things, desludging services [8, 17].

Domestic wastewater treatment services have different characteristics from private services in general. Domestic wastewater treatment services have similar characteristics as public services, namely a) nature of good/service, b) market failure, c) task, d) demand, and e) political salience. Regarding the nature of goods/services, piped domestic wastewater treatment services have a non-excludability trait, which means that it is technically challenging for communities to restrict their use as long as the pipeline network infrastructure is built. Termination of access to service in case of a debt of payments cannot be done because (a) it has a detrimental effect on environmental health, and (b) it requires a relatively large cost to terminate and restore access compared to the number of receivables 
that would be invoiced. In other words, termination of access leads to a more extensive collection cost compared to the income generated from these services.

In domestic wastewater and drinking water treatment services managed simultaneously by PDAM, the service billing is also implemented by PDAM. If a customer fails to pay the bill, it will undoubtedly be difficult to terminate the service, which is generally conducted by utilizing a piping system. It will later result in uncollectible receivables for PDAM [8, 17]. The impediment in collecting this is reflecting on the number of uncollectible receivables from domestic waste treatment services. Uncollectible receivables are claims not paid that have not been paid within 1-2 years of the account issuance, which may be submitting for reclassification/write-off. These receivable accounts continue to rise from year to year, which may cause significant problems with the PDAM's cash flow and hinder the process of providing services to the public. For PD PAL Jaya, this problem can still be resolved. Receivables that arise are generally caused by a once-a-year payment to SPALD at the household level, considering that the service fee is too small to be paid monthly [17]. For large commercial customers, receivable accounts arise due to the installment payment system for this service. Doubtful accounts generally arise when a customer moves to a new house without terminating service to PD PAL Jaya.

Along with the amount of investment required, these doubtful accounts have reduced private investors' attractiveness to conduct business in domestic wastewater treatment and explain the causes of market failure (internal failure) when the private sector provides the service. Considering all of the arguments mentioned, the government should consider providing facilities or incentives to encourage the wastewater treatment industry's growth and tax incentives for SPALD infrastructure development. It is also in line with the purposes and objectives of providing facilities in taxation, which essentially aims to provide tax facilities required, particularly for the high priority economic activity sector's success on a national scale. It is also encouraging the business and improving competitiveness, supporting national resilience, as well as accelerating national development (Elucidation of Law Number 42 the Year 2009 on The Third Amendment of Law Number 8 the Year 1983 on The Value Added Tax of Goods and Services and Tax of Luxury Goods Sale).

Fourth, the characteristics of domestic wastewater treatment services also fulfill the political salience dimension. Politically, the significance of domestic wastewater management services is not solely to achieve the SDGs target, which is the government's commitment, but also in the context of actualizing the constitutional mandate in the form of a) protecting the Indonesian people from the threat of diseases caused by an unhealthy environment due to insufficient or inadequate sanitation (Preamble to the 1945 Constitution), b) ensuring the fulfillment of the right to self-development through the fulfillment of basic needs for improving the quality of life and for the welfare of human race (Article 28C of the 1945 Constitution). Water, Sanitation, and Hygiene (WASH) are basic human needs closely linked to health and significantly impact business and the economy. It mentioned that sanitation in Indonesia depicts poor sanitation contributes to the increase in diarrheal disease. There are 120 million diarrheal disease cases each year, and even 100,000 Indonesian children are dying from it even though 94\% of the incidence of diarrhea can be prevented by increasing the supply of clean water (25\%), improving sanitation $(32 \%)$, and improving the practice of clean-living habits, especially washing hands with soap (43\%) [22].

From a sustainable environmental preservation viewpoint, it is clear that poor sanitation reduces environmental quality, also decreases the quality of the availability of adequate and safe sources of clean water. It contributes to the heavy loads economically, while poor sanitation adds to water treatment costs. Untreated wastewater produces 6 million tons of human waste per year, which is disposed of and leads to water bodies' contamination, 
making the cost of treating clean water even more expensive [22]. The data above illustrates the political salience of domestic wastewater treatment services. With the various risks of market failure, the state must provide these public services and provide fiscal incentives, either tax or non-tax.

Fifth, collecting VAT on domestic waste treatment services raises the community's burden by $10 \%$ of the value of services. This additional burden can reduce the public's interest in using domestic waste treatment services and the public's willingness to pay bills for water treatment services, particularly customers of piping services provided by PDAM. Markplus and IUWASH Plus's research also supports the public's low awareness and willingness to pay bills in 2019 concerning prospective customers' segmentation in wastewater treatment services [22]. The study reported that Indonesian people's awareness of sanitation issues from various customer segmentation is relatively low [8, 17]. In general, this research showed public apathy regarding sanitation and wastewater management issues, besides believing this issue should involve government intervention. At present, wastewater management services are subject to $10 \% \mathrm{VAT}$, which affects the $10 \%$ rise in service fees for wastewater management. It undoubtedly raises public apathy for sanitation and wastewater management issues, given that people have to pay more for services that they consider to be of little value and not a priority in people's lives.

In summary, these results show that PDPAL Jaya faces some challenges in efforts to provide wastewater management services considering its nature as public goods, namely:

1. Lack of coordination in the development of domestic wastewater management infrastructure with the piping system at the beginning of the DKI Jakarta city planning resulted in overlapping pipeline network development with other infrastructures, such as water and electricity.

2. The private sector's low participation in SPALD services in DKI Jakarta due to high investment funds and not profitable.

3. The BEP of this business is challenging to obtain in the medium and short term because of the unique characteristics of domestic wastewater treatment services, especially pipeline services.

4. Domestic wastewater management services have similar characteristics to public services. Technically, it is difficult to limit its use by the community as long as the pipeline network infrastructure is built.

5. The imposition of $10 \%$ VAT on domestic wastewater management services results in a $10 \%$ increase in service fees. It increases public apathy because they have to pay more for services that are considered unimportant and priority.

\section{Conclusion}

Poor domestic wastewater treatment would impact sustainability, both concerning water resources and ecosystem, thus generating a chain effect that disrupts human health and quality of life. Since adequate sanitation is a fundamental human right as defined by the United Nations, it is the government's responsibility to provide safe and proper wastewater treatment services. Currently, domestic wastewater treatment in DKI Jakarta is only a small part of the province's integrated piping system provided by PD PAL Jaya, given their status as a wastewater treatment operator owned by the Government of DKI Jakarta. The DKI Jakarta government, through PD PAL Jaya, has set a target to improve public access to better pipeline-based management of domestic wastewater to ensure sound environmental sanitation for the community. However, PD PAL Jaya has experienced several challenges during its implementation, including the difficulty of developing the network due to the absence of the domestic wastewater management pipeline infrastructure in DKI Jakarta's city planning. The pipeline infrastructure network's construction is experiencing difficulties 
as buildings and infrastructure for roads, railways, MRT Indonesia, and others are already developing in almost all regional areas. Also, community apathy in utilizing wastewater treatment services is exacerbated by $10 \%$ VAT imposed on these services.

Considering the characteristics of domestic wastewater treatment services that appear to be public, the government's intervention is necessary to ensure that these services are adequately provided and safely. It can be achieved by formulating financing policies that promote investment in this sector. By involving the private sector, insufficient financing in developing wastewater treatment infrastructures can be resolve. Also, coordination between ministries and agencies regarding the construction of wastewater treatment infrastructures is crucial, given that the construction is often hinder because of the overlapping construction of other pipelines (e.g., electricity and tap water). Without sufficient funding, prioritizing wastewater treatment services within the community cannot be put into practice. The needs for financing include, but are not limited to, management, supervision, policy development, capacity building, awareness-raising, and law enforcement. Further research might explore strategies to address infrastructure development problems and investment in wastewater treatment in DKI Jakarta.

\section{Acknowledgements}

This study is a part of the output of Community Engagement - Multidisciplinary Grant of 2020 (Contract No. 310/UN2.PPM/HKP.05.00/2020) funded by the Directorate of Research and Community Service of Universitas Indonesia.

\section{References}

1. J. L. Ramseur, Wastewater Infrastructure: Overview, Funding, and Legislative Developments (Congressional Research Service, 2017)

2. B. Etter, et al., Water Hub@ NEST: A living lab to test innovative wastewater treatment solutions (IWA Specialized Conferences on Small Water and Wastewater Systems \& on Resources-Oriented Sanitation, 2016)

3. Ministry of National Development Planning of the Republic of Indonesia Sustainable Development Goals (2019) http://sdgs.bappenas.go.id/

4. A. Zimmer, I.T. Winkler, and C. De Albuquerque, Governing wastewater, curbing pollution, and improving water quality for the realization of human rights, Waterl. 33 337-356 (2014)

5. K. H. Cho, et al, Achieving enhanced nitrification in communities of nitrifying bacteria in full-scale wastewater treatment plants via optimal temperature and pH, Sep. and Purif. Tech. 132 697-703 (2014)

6. World Bank, The Political economy of Sanitation: How can we increase investment and improve service for the poor (Water and Sanitation Programme World Bank, 2011)

7. Central Bureau of Statistics, Indonesian Environmental Statistics (2018)

8. Focus Group Discussion with informants, 11 November 2019 (Not published)

9. R. Q. Grafton, Pittock, Tait. J. et al, Water: Security, Economics and Governance, (Tilde University Press, 2013)

10. R. M. Musgrave, \& P. PB. Musgrave, Public finance in theory and practice (International Edition McGraw-hill Book Company, 1989) 
11. H. Rosdiana \& E. S. Irianto, Introduction to Tax Policy and Implementation in Indonesia (Jakarta, Rajawali Pers, 2014)

12. D. Moran, \& S. Dann, The economic value of water use: Implications for implementing the Water Framework Directive in Scotland, J. of Env. Mg. 87.3 484496 (2008)

13. R. C. Marques, Regulation of water and wastewater services (IWA publishing, 2010)

14. R. Batley \& C. Mcloughlin, The politics of public services: A service characteristics approach, world. Dev. 74 275-285 (2015)

15. Ministry of Public Works and Public Housing, Priority access to drinking water (2014) https://www.pu.go.id/guntingan/view/5519/akses-air-minum-diprioritaskan

16. Z. Hadianto, S. Syafrudin, \& S. Sunarsih, Evaluation and Management Strategy of Surabaya City Fecal Waste as Initial Concept for Scheduled Sludge Service Development. Diss. School of Postgrad (2019)

17. Focus Group Discussion with informants, 29 January 2020 (Not published)

18. WSP, Water and Wastewater Infrastructure (2013) https://www.wsp.com/en$\mathrm{QA} /$ services/water-infrastructure

19. UN-Water, Wastewater Management (2015) http://www.unwater.org/fileadmin/user_upload/unwater_new/docs/UNWater_Analytical_Brief_Wastewater_Management.pdf

20. K.S. Naik, M. K. Stenstrom, Evidence of the influence of wastewater treatment on improved public health, water. Sci. and Tech. 66.3 644-652 (2012)

21. UN-Water, UN-Water Annual Report (2013) https://www.unwater.org/publications/un-water-annual-report-2013/

22. USAID IUWASH PLUS (2017) https://www.iuwashplus.or.id/cms/wpcontent/uploads/2018/02/Wash-Kesehatan-dan-Bisnis-Berkelanjutan-lite-version.pdf 